\title{
Dendropanax morbifera Léveille extract ameliorates cadmium-induced impairment in memory and hippocampal neurogenesis in rats
}

Woosuk Kim¹, Hee Sun Yim², Dae Young Yoo' ${ }^{1}$, Hyo Young Jung ${ }^{1}$, Jong Whi Kim¹', Jung Hoon Choi ${ }^{3}$, Yeo Sung Yoon', Dae Won Kim² and In Koo Hwang ${ }^{1,4^{*}}$ (D)

\begin{abstract}
Background: Cadmium leads to learning and memory impairment. Dendropanax morbifera Léveille stem extract (DMS) reduces cadmium-induced oxidative stress in the hippocampus. We investigated the effects of DMS on cadmium-induced impairments in memory in rats.

Methods: Cadmium (2 mg/kg), with or without DMS (100 mg/kg), was orally administered to 7-week-old Sprague-Dawley rats for 28 days. Galantamine $(5 \mathrm{mg} / \mathrm{kg})$, an acetylcholinesterase inhibitor, was intraperitoneally administered as a positive control. A novel-object recognition test was conducted $2 \mathrm{~h}$ after the final administration. Cell proliferation and neuroblast differentiation were assessed by immunohistochemistry for Ki67 and doublecortin, respectively. Acetylcholinesterase activity in the synaptosomes of the hippocampus was also measured based on the formation of 5,5'-dithio-bis-acid nitrobenzoic acid.

Results: An increase in the preferential exploration time of new objects was observed in both vehicle-treated and cadmium-treated rats. In addition, DMS administration increased cell proliferation and neuroblast differentiation in the dentate gyrus of vehicle-treated and cadmium-treated rats. Acetylcholinesterase activity in the hippocampal synaptosomes was also significantly higher in the DMS-treated group than in the vehicle-treated group. The effect of DMS on cadmiuminduced memory impairment and cell proliferation in the hippocampus was comparable to that of galantamine.

Conclusions: These results suggest that DMS ameliorates cadmium-induced memory impairment via increase in cell proliferation, neuroblast differentiation, and acetylcholinesterase activity in the hippocampus. The consumption of DMS may reduce cadmium-induced neurotoxicity in animals or humans.
\end{abstract}

Keywords: Dendropanax morbifera extract, Cadmium, Neurogenesis, Memory, Acetylcholinesterase

\section{Background}

Improvements in medical technology have caused sharp increases in the population of humans aged 65 years and above, and South Korea is becoming one of the most rapidly aging societies in the world. One of the most important problems in an aging society is the decrease

\footnotetext{
* Correspondence: vetmed2@snu.ac.kr

'Department of Anatomy and Cell Biology, College of Veterinary Medicine, and Research Institute for Veterinary Science, Seoul National University, Seoul 08826, South Korea

${ }^{4}$ Department of Anatomy and Cell Biology, College of Veterinary Medicine, Seoul National University, Seoul 08826, South Korea

Full list of author information is available at the end of the article
}

in quality of life caused by mild cognitive impairment or the cognitive symptoms of neuropsychiatric disorders, such as schizophrenia $[1,2]$. Some therapeutic agents, including donepezil, galantamine (GAL), and memantine, improve cognitive function in Alzheimer's disease $[1,2]$. However, natural extracts or compounds have been recent targets of research because of their potential for fewer associated side effects compared to many chemical compounds.

Several lines of evidence suggest that newly generated cells in the subgranular zone of the dentate gyrus can proliferate, differentiate, and integrate into the granule 
cell layer, where they participate in hippocampal functions, such as learning and memory $[3,4]$. Proliferating cells with active cell cycles in the subgranular zone of the dentate gyrus express Ki67 [5] and adult-born neuroblasts express doublecortin (DCX) from days 1 to 28 of cell age [6,7]. The rate of neurogenesis in the hippocampus is associated with spatial-memory consolidation [8]. The novel-object recognition test is one of most reliable methods of measuring hippocampal-dependent memory because animals remember the familiar object and increase their explorative activity (approach frequency and time spent exploring the novel object) [9]. Adult neurogenesis is required only when the reactivation session involves novelty and this process drives the updating of stored object recognition memories. Stimulation of endogenous hippocampal neurogenesis reinforces the hippocampal network and improves learning and memory, whereas ablation of hippocampal neurogenesis by $\gamma$-ray irradiation of the dentate gyrus leads to cognitive impairment [10-13]. In particular, the inhibition of WNT signaling by dominant-negative WNT significantly reduces novel-object recognition memory [13].

Dendropanax morbifera Léveille is an endemic plant found in southwestern Korea. The plant has been used in traditional medicine for the treatment of skin problems, infectious diseases, headaches, and other maladies [14]. D. morbifera Léveille stem extract (DMS) decreases free radical damage in various organs, including the hippocampus $[15,16]$. In previous studies, we demonstrated that DMS facilitates the excretion of cadmium and reduces cadmium-induced oxidative damage in the hippocampus [15].

Cadmium is one of the most harmful heavy metals because it increases the permeability of the blood-brain barrier and penetrates the brain, leading to intracellular accumulation, cellular dysfunction, and cerebral edema [16-18]. The potential protective effects of DMS on hippocampal function and neuroblast differentiation after cadmium exposure have not been examined. Therefore, in this study, we established a model of cadmiuminduced memory impairment in rats and investigated the effects of DMS administration on cell proliferation and neuroblast differentiation in the rat dentate gyrus after cadmium exposure.

\section{Methods}

\section{Experimental animals}

Male Sprague-Dawley rats were purchased from Orient Bio Inc. (Seongnam, South Korea). Rats were housed in a conventional animal facility at $23{ }^{\circ} \mathrm{C}$ with $60 \%$ humidity, a 12 h/12 h light/dark cycle, with ad libitum access to food and tap water. The handling and care of the animals conformed to guidelines established in compliance with current international laws and policies $(\mathrm{NIH}$
Guide for the Care and Use of Laboratory Animals, NIH Publication No. 85-23, 1985, revised 1996) and were approved by the Institutional Animal Care and Use Committee of Seoul National University (SNU-130522-1). All experiments were conducted with an effort to minimize the number of animals used and the suffering caused by the procedures used in the study.

\section{Preparation of DMS}

Fresh D. morbifera Léveille was obtained from Hambakjae Farm (Jeju, Korea). The plant was authenticated by two practitioners of traditional Asian medicine and a voucher specimen was deposited in our laboratory (Deposition number: 2012-030). Stems from the plant samples (100 g) were chopped, blended, soaked in $2 \mathrm{~L}$ of $80 \%$ ethanol, and refluxed thrice at $20{ }^{\circ} \mathrm{C}$ for $2 \mathrm{~h}$. Insoluble materials were removed by centrifugation at $10,000 \mathrm{~g}$ for $30 \mathrm{~min}$, and the resulting supernatant was concentrated and freeze-dried to yield a powder (yield: $3.3 \%$ ). Before each experiment, the dried extract was dissolved in distilled and deionized water.

\section{Administration of cadmium, DMS, and GAL}

Cadmium chloride $\left(\mathrm{CdCl}_{2}\right)$ was obtained from SigmaAldrich (St. Louis, MO, USA). Animals were divided into 5 treatment groups ( $n=10$ in each group): 1$)$ treatment with vehicle (distilled water); 2) treatment with $100 \mathrm{mg} / \mathrm{kg}$ DMS; 3) treatment with $2 \mathrm{mg} / \mathrm{kg} \mathrm{CdCl}$; 4) treatment with $\mathrm{CdCl}_{2}$ and DMS; and 5) treatment with $\mathrm{CdCl}_{2}$ and $5 \mathrm{mg} / \mathrm{kg} \mathrm{GAL}$ (Sigma-Aldrich). Cadmium and DMS were dissolved in distilled water and administered to 7-week-old rats, once a day for 28 days using a gavage, while GAL was dissolved in physiological saline and administered intraperitoneally for 28 days. GAL was used as a positive control in this study, owing to its action as an acetylcholinesterase (AChE) inhibitor and its ability for improving memory and promoting neurogenesis as demonstrated previously [19-21].

\section{Novel-object recognition test}

The test was performed as described by Foyet et al. [22]. The apparatus consisted of an open box $(80 \times 80 \times$ $40 \mathrm{~cm}$ high) made of black acryl. The floor was covered with woodchip bedding, which was moved around between trials and testing days to prevent the build-up of odor in certain places. The objects to be discriminated were made of a solid metal, and their weight ensured that the rats could not displace them. The objects were cleaned with bleach to remove the smell of the rats.

After 25 days of vehicle, cadmium, DMS and/or GAL treatment, each rat was allowed to explore the apparatus for $2 \mathrm{~min}$. On the testing day (at 28 days of treatment), $2 \mathrm{~h}$ following the final treatment, a session of two trials, 2 min each, was carried out. In the "sample" trial (T1), 2 identical objects were placed in opposite corners of the 
apparatus. A rat was placed in the apparatus and was left to explore these two identical objects. After T1, the rat was placed back in its home cage and an inter-trial interval of $1 \mathrm{~h}$ was given. Subsequently, the "choice" trial (T2) was performed. In T2, a new object replaced one of the objects that had been presented in $\mathrm{T} 1$. The rats were exposed to the two different objects: one familiar and one new. Exploration was defined as directing the nose toward the object at a distance of no more than $2 \mathrm{~cm}$ and/or touching the object with the nose. From these measurements, a series of variables were calculated: the total time spent exploring the 2 identical objects in $\mathrm{T} 1$ and time spent exploring the 2 different objects, familiar and new, in $\mathrm{T} 2$.

The distinction between familiar and new objects in T2 was determined by comparing the time spent exploring familiar objects with that spent exploring $\mathrm{N}$. The discrimination index (DI) represents the difference in exploration time expressed as a proportion of the total time spent exploring the two objects in T2.

\section{Tissue processing}

For histology, the animals ( $n=5$ in each group) were anesthetized by an intraperitoneal injection of $1 \mathrm{~g} / \mathrm{kg}$ urethane (Sigma-Aldrich) directly after the novelobject recognition test. Rats were perfused transcardially with $0.1 \mathrm{M}$ phosphate-buffered saline (PBS, $\mathrm{pH}$ 7.4) followed by $4 \%$ paraformaldehyde in $0.1 \mathrm{M}$ PBS. The brains were dissected out and postfixed in the same fixative for $12 \mathrm{~h}$. The brain tissues were cryoprotected by infiltration with $30 \%$ sucrose overnight. Thirty-micrometer thick brain sections were serially sectioned in the coronal plane using a cryostat (Leica, Wetzlar, Germany) and collected in six-well plates containing PBS for further processing.

\section{Immunohistochemistry for Ki67 and DCX}

To obtain accurate data for immunohistochemistry, the free-floating sections from all animals were processed carefully under the same conditions. Tissue sections were selected between 3.00 and $4.08 \mathrm{~mm}$ posterior to the bregma with reference to a rat brain atlas [23] for each animal. Ten sections, 90- $\mu \mathrm{m}$ apart from each other, were sequentially treated with $0.3 \%$ hydrogen peroxide $\left(\mathrm{H}_{2} \mathrm{O}_{2}\right)$ in PBS for 30 min and $10 \%$ normal horse serum in $0.05 \mathrm{M}$ PBS for $30 \mathrm{~min}$. They were then incubated with a rabbit anti-Ki67 antibody (1:1,000; Abcam, Cambridge, UK) or goat anti-DCX antibody (1:50; Santa Cruz Biotechnology, Santa Cruz, CA) overnight at $25{ }^{\circ} \mathrm{C}$ and subsequently treated with either a biotinylated goat anti-mouse IgG or horse anti-goat IgG, and a streptavidinperoxidase complex (1:200, Vector, Burlingame, CA). Sections were visualized by reaction with 3,3'-diaminobenzidine tetrachloride (Sigma) in $0.1 \mathrm{M}$ Tris- $\mathrm{HCl}$ buffer (pH 7.2) and dehydrated and mounted in Canada balsam (Kanto, Tokyo, Japan) onto gelatincoated slides.

The Ki67-positive cells were enumerated using an image-analysis system equipped with a computer-based CCD camera and Optimas 6.5 software (CyberMetrics, Scottsdale, AZ). The Ki67-positive cells in each section of the dentate gyrus were enumerated using the software protocol (CyberMetrics). The cell-counts from all of the sections for each treatment group were averaged into a single group mean.

\section{Measurement of AChE activity in the hippocampus}

To measure AChE activity in synaptosomes, animals in each group $(n=5)$ were anesthetized with $1 \mathrm{~g} / \mathrm{kg}$ urethane (Sigma-Aldrich) after the novel-object recognition test, and the hippocampi were quickly removed from the brain and placed into labeled cryo-tubes. After a quick-freeze in liquid nitrogen for $15 \mathrm{~min}$, the hippocampi were homogenized in 10 volumes of an ice-cold medium (medium I), consisting of $320 \mathrm{mM}$ sucrose, $0.1 \mathrm{mM}$ ethylenediaminetetraacetic acid, and 5 mM 4-(2-hydroxyethyl)-1-piperazineethanesulfonic acid, $\mathrm{pH} 7.5$, in a motor driven Teflon-glass homogenizer. Synaptosomes were isolated using a discontinuous Percoll gradient, as described by Nagy and DelgadoEscueta [24]. The pellet was suspended in an isoosmotic solution, and the final protein concentration was adjusted to $0.5 \mathrm{mg} / \mathrm{mL}$. Synaptosomes were prepared fresh daily, maintained at $4{ }^{\circ} \mathrm{C}$ throughout the procedure, and used for enzymatic assays. The AChE enzymatic assay was conducted using a modification of the spectrophotometric method of Ellman et al. [25], as described by Rocha et al. [26]. The reaction mixture ( $2 \mathrm{~mL}$ final volume) contained $100 \mathrm{mM} \mathrm{K}^{+}$-phos-

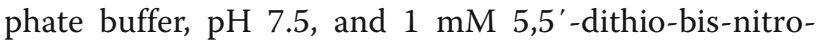
benzoic acid. The method is based on the formation of the yellow anion, 5,5'-dithio-bis-acid nitrobenzoic, measured by reading absorbance at $412 \mathrm{~nm}$ during a 2-min incubation at $25{ }^{\circ} \mathrm{C}$. The enzyme was preincubated for $2 \mathrm{~min}$, and the reaction was initiated by adding $0.8 \mathrm{mM}$ acetylthiocholine iodide (AcSCh). All samples were run in duplicate or triplicate and enzyme activity was expressed in $\mu \mathrm{mol} \mathrm{AcSCh} / \mathrm{h} / \mathrm{mg}$ of protein.

\section{Statistical analysis}

All data are expressed as the mean \pm standard error of the mean (SEM). To determine the effects of cadmium, DMS, and GAL treatments, differences between the means were analyzed using one-way analysis of variance with repeated measures and a Bonferroni's post-hoc test. Differences were considered significant if $p \leq 0.05$. 


\section{Results}

Effects of cadmium with or without DMS on recognition memory

During the training period, all rats showed similar behavioral patterns and spent a similar fraction of time exploring the identical objects, although the cadmiumtreated group, with or without DMS, showed less activity exploring the objects compared to the control group. During the test period, rats in the control and DMStreated group spent more time exploring new objects than familiar ones. In the cadmium-treated group, rats spent a similar amount of time exploring new and familiar objects and the DI was decreased significantly compared to that in the control group. In contrast, rats in the group treated with cadmium and DMS spent more time exploring new objects than familiar ones and the DI was increased significantly in this group compared to that of the cadmium-treated group. Rats in the group treated with cadmium and GAL also spent more time exploring new objects and the DI was increased in this group compared to that of the cadmium-treated group. In the cadmium and GAL group, the DI was similar to that in the group treated with cadmium and DMS $\left(F=17.87, \mathrm{df}_{\text {total }}=49, \mathrm{df}_{\text {treatment }}=4\right)($ Fig. 1$)$.

\section{Effects of cadmium and/or DMS on cell proliferation in the dentate gyrus}

In the vehicle-treated group, clustered Ki67-positive nuclei were detected in the subgranular zone of the dentate gyrus (Fig. 2a). In this group, the number of Ki67-positive nuclei was $15.6 \pm 0.78$ per section of the dentate gyrus. In the DMS-treated group, the number of Ki67-positive nuclei within the dentate gyrus showed a significant increase of $52.3 \%$ compared to that in the vehicle-treated group (Fig. $2 \mathrm{~b}$ and $\mathrm{f}$ ). In the cadmiumtreated group, few Ki67-positive nuclei were detectable in the dentate gyrus, equivalent to only $28.4 \%$ of that found in the vehicle-treated group (Fig. 2c and f). In the group treated with cadmium and DMS, the number of Ki67-positive nuclei was increased significantly in the dentate gyrus compared to that in the cadmium-treated group, although the number was lower than that in the vehicle-treated group (Fig. $2 \mathrm{~d}$ and $\mathrm{f}$ ). In the group treated with cadmium and GAL, the number of Ki67positive nuclei was also significantly increased in the dentate gyrus compared to that in the cadmium-treated group and the number of Ki67-positive nuclei was similar to the group treated with cadmium and DMS $\left(F=55.07, \mathrm{df}_{\text {total }}=34, \mathrm{df}_{\text {treatment }}=4\right)($ Fig. $2 \mathrm{e}$ and $\mathrm{f})$.

\section{Effects of cadmium and/or DMS on neuroblast differentiation in the dentate gyrus}

In the vehicle-treated group, DCX-immunoreactive neuroblasts were detected in the subgranular zone of the

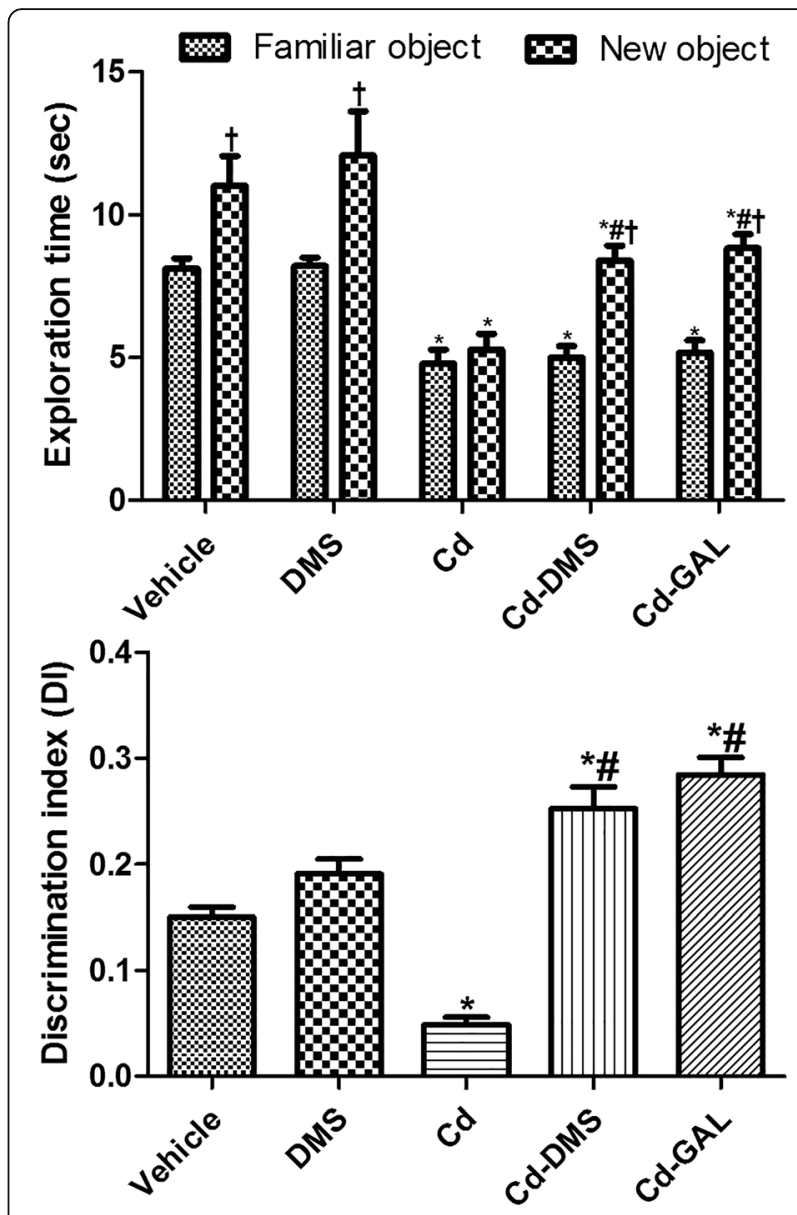

Fig. 1 Effect of treatment on exploration time and discrimination index of familiar vs. new objects in the novel-object recognition test in rats. *indicates a significant difference between the vehicle-treated and cadmium (Cd)-treated groups; ${ }^{*}$ indicates a significant difference

between the vehicle and Dendropanax morbifera Léveille stem extract (DMS) (or galantamine [GAL]) treatment groups; † indicates a significant difference between the familiar and new object $(p<0.05 ; n=10$ per group). The data are shown as mean \pm SEM

dentate gyrus, and their well-developed dendrites extended into two-thirds of the molecular layer of the dentate gyrus (Fig. 3a and b). In the DMS-treated group, the distribution pattern of neuroblasts and dendrites in the dentate gyrus were similar to those in the vehicle-treated group (Fig. 3c and d). However, in the cadmium-treated group, DCX-immunoreactive neuroblasts showed a decrease in number and a shortening of the dendrites in the dentate gyrus compared to those in the vehicletreated group (Fig. 3e and $\mathrm{f}$ ). In the group treated with cadmium and DMS, the DCX-immunoreactive neurons had well-developed dendrites and the number of DCXimmunoreactive neurons significantly increased compared to that in the cadmium-treated group (Fig. $3 \mathrm{~g}$ and $\mathrm{h}$ ). In the group treated with cadmium and GAL, DCXimmunoreactive neurons were abundantly observed in the 

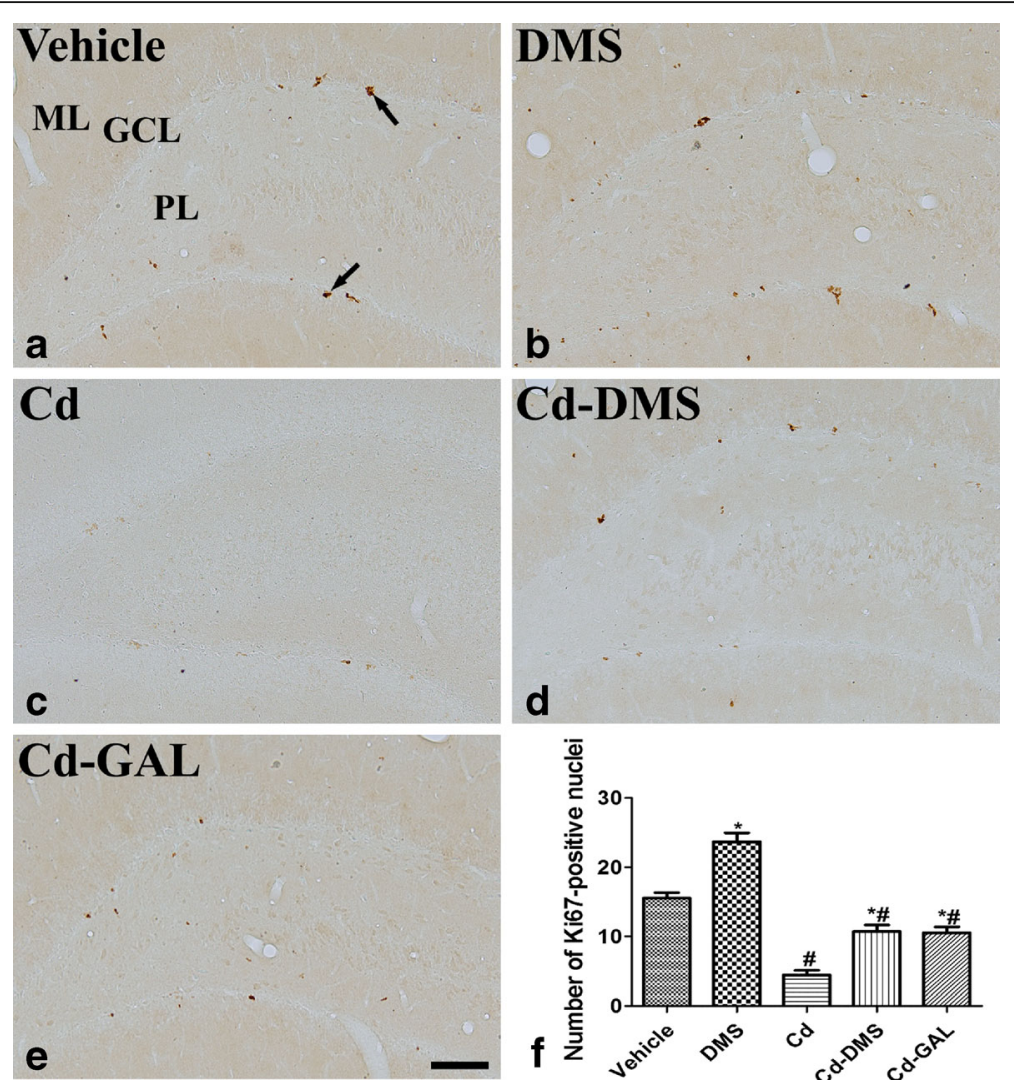

Fig. 2 Immunohistochemistry for Ki67 in the dentate gyrus of treated rats. Ki67 immunostaining in rats treated with vehicle (a), Dendropanax morbifera Léveille stem extract (DMS; b), cadmium alone (Cd; c), cadmium and DMS (Cd-DMS; d), and cadmium plus galantamine (Cd-GAL) (e). In the vehicle-treated group, Ki67-positive nuclei (arrows) are detectable in the subgranular zone of the dentate gyrus. Note that there are few Ki67-positive nuclei in the Cd-treated group; however, they are comparatively abundant in the Cd-DMS-treated and Cd-GAL-treated groups. GCL, granule cell layer; ML, molecular layer; PoL, polymorphic layer. Scale bar $=100 \mu \mathrm{m}$. f: Quantitative analysis of Ki67-positive nuclei per section in the vehicle, DMS-treated, Cd-treated, DMS-Cd-treated, and DMS-GAL-treated rats using an image analyzer ( $n=5$ per group); ${ }^{*}$ indicates a significant difference between the vehicle and $\mathrm{Cd}$ groups $(p<0.05)$; ${ }^{\#}$ indicates a significant difference between the vehicle and DMS (or GAL) groups ( $p<0.05 ; n=5$ per group). The data are shown as mean \pm SEM

dentate gyrus, and they also had well-developed dendrites compared to those in the cadmium-treated group (Fig. 3i and j).

\section{Effects of cadmium and/or DMS on AChE activity in the hippocampal homogenates}

In the vehicle-treated group, AChE activity was $4.47 \mu \mathrm{mol} \mathrm{AcSCh} / \mathrm{h} / \mathrm{mg}$ protein in the hippocampal homogenates. In the DMS-treated group, this activity was higher than that in the vehicle-treated group; however, a significant difference was not found. In the cadmiumtreated group, AChE activity was decreased significantly to $56.4 \%$ of that in vehicle-treated group. In the cadmium and DMS-treated group, as well as in the groups treated with cadmium and GAL, AChE activity showed a significant increase of $55.6 \%$ and $72.2 \%$, respectively, compared to that of the cadmium-treated group $\left(F=11.36, \mathrm{df}_{\text {total }}=24, \mathrm{df}_{\text {treatment }}=4\right)($ Fig. 4$)$.

\section{Discussion}

Cadmium readily accumulates in tissues (with an approximately 30-year half-life in humans), including the vascular endothelium of the brain, where it effects the integrity and permeability of the blood-brain barrier $[17,27-29]$. In the present study, we observed the effects of cadmium on hippocampal function based on novel-object recognition memory. We observed that the administration of cadmium caused decreased exploratory activity, as well as a decrease in novel object recognition. This result is consistent with that of previous studies that showed that acute administration of cadmium had depressogenic effects and decreased locomotor activity [30, 31]. In addition, cadmium decreases cognitive functions in humans [32] and induces neuronal death in basal forebrain cholinergic neurons [33]. Furthermore, cadmium treatment facilitates an increase in the number and size of senile plaques and promotes memory impairments [34]. In the present study, 


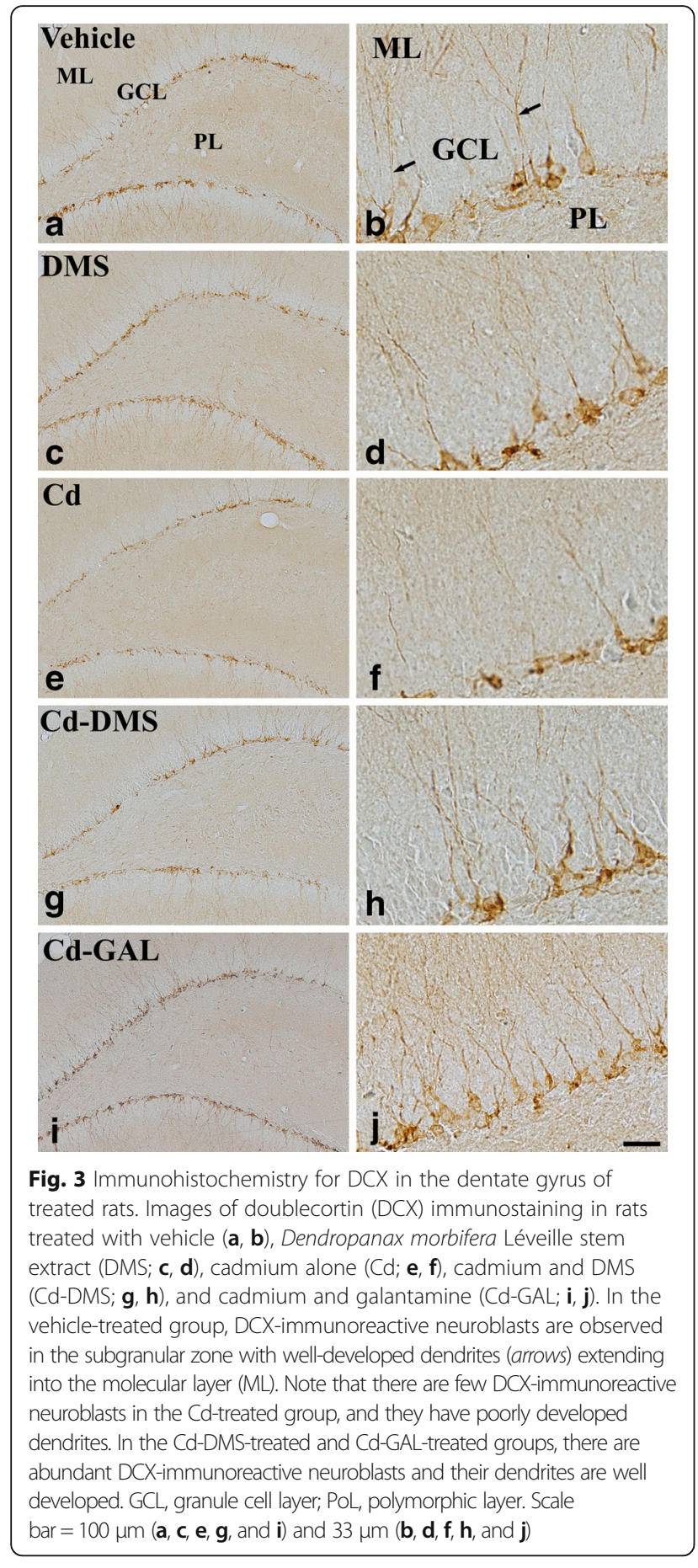

the administration of cadmium with DMS ameliorated the decreased locomotor activity and improved the DI in a novel-object recognition test. $D$. morbifera extract is shown to have neuroprotective effects against heavy metal-induced oxidative damage $[15,35]$ and rotenoneinduced dopaminergic cell death [36]. Extracts from the leaves and stems of $D$. morbifera decreases both cadmium-induced and mercury-induced oxidative damage

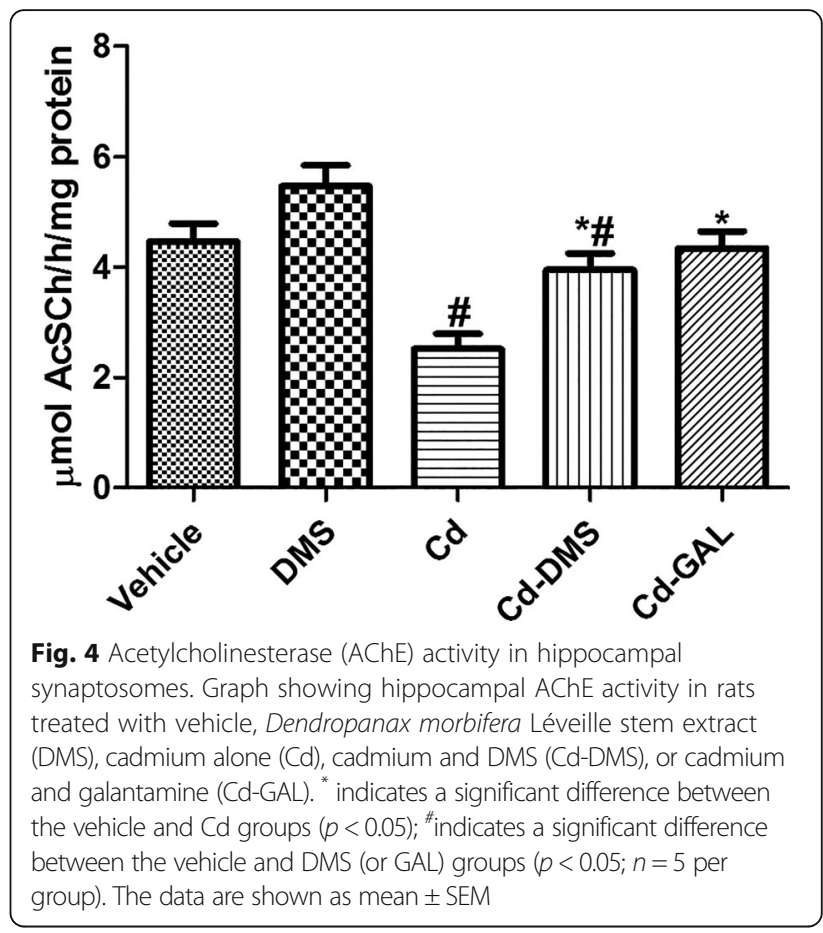

in the hippocampus $[15,35]$. Furthermore, rutin, isolated from $D$. morbifera Léveille, significantly decreased rotenone-induced dopaminergic cell death by ameliorating rotenone-induced c-Jun N-terminal kinase and p38 mitogen-activated protein kinase phosphorylation in SH-SY5Y cells [36].

Rapid depletion of actively dividing neurogenic cells and approximately $90 \%$ of DCX-expressing cells by $\mathrm{X}$-ray irradiation significantly decreases novel-object recognition [37]. In addition, the temporal requirement (i.e., 3 days) of neurogenesis after reactivation for reconsolidation is the same as that found for consolidation [38]. During novel-object recognition, the hippocampus is involved in the identification of spatial changes in object position and detection of novelty [39]. In the present study, we studied the effects of cadmium on the hippocampus because it is one of the brain regions most vulnerable to toxic materials. The administration of cadmium significantly reduced cell proliferation, neuroblast differentiation, and AChE activity in the hippocampus. Previous reports indicated that exposure to cadmium decreases AChE activity, increases oxidative damage in the hippocampus [18], and reduces neuronal differentiation and axonogenesis during embryonic brain development of zebrafish [40]. However, this is the first report of cadmium affecting neurogenesis in the adult brain.

Extracts from the leaves of $D$. morbifera suppress the production of pro-inflammatory cytokines and increase anti-inflammatory marker genes in lipopolysaccharidestimulated BV2 cells [41]. In the present study, we also 
investigated the effects of DMS on the cadmium-induced decrease in hippocampal function. Administration of DMS significantly ameliorated cadmium-induced impairment of novel-object recognition memory. In addition, DMS increased cell proliferation, neuroblast differentiation, and $\mathrm{AChE}$ activity in the hippocampus, thus countering the effects of cadmium exposure. DMS had a comparable potency to GAL in terms of increasing cell proliferation, neuroblast differentiation, and $\mathrm{AChE}$ activity in the hippocampus. GAL has been reported to increase neurogenesis in the subgranular zone of the dentate gyrus and in the subventricular zone of the lateral ventricle [19-21]. Collectively, our results suggest that the administration of DMS significantly increases cell proliferation and neuroblast differentiation by promoting AChE activity in the dentate gyrus, where $\mathrm{AChE}$ is highly expressed in proliferating and differentiating cells and is likely involved in neurite outgrowth [42-44]. This conclusion is supported by previous studies that showed that AChE is involved in progenitor-cell proliferation and differentiation [45], and modulation of the cholinergic system significantly alters hippocampal neurogenesis [46, 47]. The mechanism of DMS action was not demonstrated in this study; however, DMS has possible neuroprotective effects against cadmium-induced neurotoxicity. Rutin and/or its metabolites, components arising from DMS, are able to cross the blood brain barrier [48, 49], and rutin may reduce memory deficits in Alzheimer's disease [50].

\section{Conclusion}

Repeated exposure to cadmium causes memory impairment and reduces cell proliferation, neuroblast differentiation, and AChE activity. The administration of DMS effectively ameliorates these cadmium-induced effects by maintaining AChE activity in the hippocampus.

\section{Abbreviation}

AChE: Acetylcholinesterase; AcSCh: Acetylthiocholine iodide; DCX: Doublecortin; DI: Discrimination index; DMS: D. morbifera stem extract; GAL: Galantamine; PBS: Phosphate-buffered saline; SEM: Standard error of the mean

\section{Funding}

This Research was supported by High Value-added Food Technology Development Program, Ministry for Agriculture, Food and Rural Affairs, Republic of Korea (112106-022-HD020). This study was partially supported by the Research Institute for Veterinary Science, Seoul National University.

\section{Availability of data and materials}

The supporting materials including Dendropanax morbifera Léveille extract can be obtained upon request via email to the corresponding authors.

\section{Authors' contributions}

WK, HSY, DYY, HYJ, JWK, JHC, YSY, DWK, and IKH conceived the study. WK and IKH designed the study. WK, DYY, HYJ, JWK conducted the animal experiments and HSY and DWK measured acetylcholinesterase activity. JHC and YSY participated in designing and discussing the study. All authors have read and approved the final manuscript.

\section{Competing interests}

The authors declare that they have no competing interests.

\section{Consent for publication}

This information is not relevant.

\section{Ethics approval and consent to participate}

The handling and care of the animals conformed to the guidelines established to comply with current international laws and policies $(\mathrm{NIH}$ Guide for the Care and Use of Laboratory Animals, NIH Publication No. 85-23, 1985, revised 1996) and were approved by the Institutional Animal Care and Use Committee of Seoul National University (Approval number: SNU-130522-1).

\section{Author details}

'Department of Anatomy and Cell Biology, College of Veterinary Medicine, and Research Institute for Veterinary Science, Seoul National University, Seoul 08826, South Korea. ${ }^{2}$ Department of Biochemistry and Molecular Biology, Research Institute of Oral Sciences, College of Dentistry, Kangneung-Wonju National University, Gangneung 25457, South Korea. ${ }^{3}$ Department of Anatomy, College of Veterinary Medicine, Kangwon National University, Chuncheon 24341, South Korea. ${ }^{4}$ Department of Anatomy and Cell Biology, College of Veterinary Medicine, Seoul National University, Seoul 08826, South Korea.

Received: 27 April 2016 Accepted: 2 November 2016

Published online: 09 November 2016

\section{References}

1. Rubio MD, Drummond JB, Meador-Woodruff JH. Glutamate receptor abnormalities in schizophrenia: implications for innovative treatments. Biomol Ther. 2012;20:1-18.

2. Schwarz S, Froelich L, Burns A. Pharmacological treatment of dementia. Curr Opin Psychiatry. 2012;25:542-50.

3. Deng W, Aimone JB, Gage FH. New neurons and new memories: how does adult hippocampal neurogenesis affect learning and memory? Nat Rev Neurosci. 2010:11:339-50.

4. Leuner B, Gould E, Shors TJ. Is there a link between adult neurogenesis and learning? Hippocampus. 2006;16:216-24.

5. Kee N, Sivalingam S, Boonstra R, Wojtowicz JM. The utility of Ki-67 and BrdU as proliferative markers of adult neurogenesis. J Neurosci Methods. 2002;115:97-105.

6. Brown JP, Couillard-Després S, Cooper-Kuhn CM, Winkler J, Aigner L, Kuhn HG. Transient expression of doublecortin during adult neurogenesis. J Comp Neurol. 2003;467:1-10.

7. Couillard-Despres S, Winner B, Schaubeck S, Aigner R, Vroemen M, Weidner N, Bogdahn U, Winkler J, Kuhn HG, Aigner L. Doublecortin expression levels in adult brain reflect neurogenesis. Eur J Neurosci. 2005:21:1-14.

8. Sarkisyan G, Hedlund PB. The 5-HT7 receptor is involved in allocentric spatial memory information processing. Behav Brain Res. 2009:202:26-31.

9. Ennaceur A. One-trial object recognition in rats and mice: methodological and theoretical issues. Behav Brain Res. 2010;215:244-54.

10. Acharya MM, Christie LA, Hazel TG, Johe KK, Limoli CL. Transplantation of human fetal-derived neural stem cells improves cognitive function following cranial irradiation. Cell Transplant. 2014;23:1255-66.

11. Raber J, Rola R, LeFevour A, Morhardt D, Curley J, Mizumatsu S, VandenBerg SR, Fike JR. Radiation-induced cognitive impairments are associated with changes in indicators of hippocampal neurogenesis. Radiat Res. 2004:162:39-47.

12. Seo DO, Carillo MA, Chih-Hsiung Lim S, Tanaka KF, Drew MR. Adult hippocampal neurogenesis modulates fear learning through associative and nonassociative mechanisms. J Neurosci. 2015;35:11330-45.

13. Jessberger S, Clark RE, Broadbent NJ, Clemenson Jr GD, Consiglio A, Lie DC, Squire LR, Gage FH. Dentate gyrus-specific knockdown of adult neurogenesis impairs spatial and object recognition memory in adult rats. Learn Mem. 2009:16:147-54.

14. Park BY, Min BS, Oh SR, Kim JH, Kim TJ, Kim DH, Bae KH, Lee HK. Isolation and anticomplement activity of compounds from Dendropanax morbifera. J Ethnopharmacol. 2004;90:403-8.

15. Kim W, Kim DW, Yoo DY, Jung HY, Nam SM, Kim JW, Hong SM, Kim DW, Choi JH, Moon SM, Yoon YS, Hwang IK. Dendropanax morbifera Léveille 
extract facilitates cadmium excretion and prevents oxidative damage in the hippocampus by increasing antioxidant levels in cadmium-exposed rats. BMC Complement Altern Med. 2014;14:428.

16. Shukla GS, Chandra SV. Concurrent exposure to lead, manganese, and cadmium and their distribution to various brain regions, liver, kidney, and testis of growing rats. Arch Environ Contam Toxicol. 1987;16:303-10.

17. Méndez-Armenta M, Ríos C. Cadmium neurotoxicity. Environ Toxicol Pharmacol. 2007;23:350-8.

18. Gonçalves JF, Fiorenza AM, Spanevello RM, Mazzanti CM, Bochi GV, Antes FG, Stefanello N, Rubin MA, Dressler VL, Morsch VM, Schetinger MR. Nacetylcysteine prevents memory deficits, the decrease in acetylcholinesterase activity and oxidative stress in rats exposed to cadmium. Chem Biol Interact. 2010;186:53-60.

19. Jin K, Xie L, Mao XO, Greenberg DA. Alzheimer's disease drugs promote neurogenesis. Brain Res. 2006;1085:183-8.

20. Yoo DY, Woo YJ, Kim W, Nam SM, Lee BH, Yeun GH, Yoon YS, Won MH, Park JH, Hwang IK. Effects of a new synthetic butyrylcholinesterase inhibitor, $\mathrm{HBU}-39$, on cell proliferation and neuroblast differentiation in the hippocampal dentate gyrus in a scopolamine-induced amnesia animal model. Neurochem Int. 2011;59:722-8.

21. Yoo DY, Choi JH, Kim W, Nam SM, Jung HY, Kim JH, Won MH, Yoon YS, Hwang IK. Effects of luteolin on spatial memory, cell proliferation, and neuroblast differentiation in the hippocampal dentate gyrus in a scopolamine-induced amnesia model. Neurol Res. 2013;35:813-20.

22. Foyet HS, Ngatanko Abaïssou HH, Wado E, Asongalem Acha E, Alin C. Emilia coccinae (SIMS) G Extract improves memory impairment, cholinergic dysfunction, and oxidative stress damage in scopolamine-treated rats. BMC Complement Altern Med. 2015;15:333.

23. Paxinos G, Watson C. The rat brain in stereotaxic coordinates. Amsterdam: Elsevier Academic Press; 2007.

24. Nagy A, Delgado-Escueta AV. Rapid preparation of synaptosomes from mammalian brain using nontoxic isoosmotic gradient material (Percoll). J Neurochem. 1984;43:1114-23

25. Ellman GL, Courtney KD, Andres Jr V, Feather-Stone RM. A new and rapid colorimetric determination of acetylcholinesterase activity. Biochem Pharmacol. 1961;7:88-95.

26. Rocha JB, Emanuelli T, Pereira ME. Effects of early undernutrition on kinetic parameters of brain acetylcholinesterase from adult rats. Acta Neurobiol Exp (Wars). 1993;53:431-7.

27. Shukla A, Shukla GS, Srimal RC. Cadmium-induced alterations in blood-brain barrier permeability and its possible correlation with decreased microvessel antioxidant potential in rat. Hum Exp Toxicol. 1996;15:400-5.

28. Usai C, Barberis A, Moccagatta L, Marchetti C. Pathways of cadmium influx in mammalian neurons. J Neurochem. 1999;72:2154-61.

29. Yoshida S. Re-evaluation of acute neurotoxic effects of $\mathrm{Cd}^{2+}$ on mesencephalic trigeminal neurons of the adult rat. Brain Res. 2001;892:102-10.

30. Dési l, Nagymajtényi L, Schulz H. Behavioural and neurotoxicological changes caused by cadmium treatment of rats during development. J Appl Toxicol. 1998:18:63-70.

31. Haider S, Anis L, Batool Z, Sajid I, Naqvi F, Khaliq S, Ahmed S. Short term cadmium administration dose dependently elicits immediate biochemical, neurochemical and neurobehavioral dysfunction in male rats. Metab Brain Dis. 2015;30:83-92.

32. Ciesielski T, Bellinger DC, Schwartz J, Hauser R, Wright RO. Associations between cadmium exposure and neurocognitive test scores in a crosssectional study of US adults. Environ Health. 2013;12:13.

33. Del Pino J, Zeballos G, Anadon MJ, Capo MA, Díaz MJ, García J, Frejo MT. Higher sensitivity to cadmium induced cell death of basal forebrain cholinergic neurons: a cholinesterase dependent mechanism. Toxicology. 2014;325:151-9.

34. Li X, LV Y, Yu S, Zhao $H$, Yao L. The effect of cadmium on $A \beta$ levels in APP/PS1 transgenic mice. Exp Ther Med. 2012;4:125-30.

35. Kim W, Kim DW, Yoo DY, Jung HY, Kim JW, Kim DW, Choi JH, Moon SM, Yoon YS, Hwang IK. Antioxidant effects of Dendropanax morbifera Léveille extract in the hippocampus of mercury-exposed rats. BMC Complement Altern Med. 2015:15:247

36. Park SE, Sapkota K, Choi JH, Kim MK, Kim YH, Kim KM, Kim KJ, Oh HN, Kim SJ, Kim S. Rutin from Dendropanax morbifera Leveille protects human dopaminergic cells against rotenone induced cell injury through inhibiting JNK and p38 MAPK signaling. Neurochem Res. 2014:39:707-18.
37. Suárez-Pereira I, Carrión ÁM. Updating stored memory requires adult hippocampal neurogenesis. Sci Rep. 2015:5:13993.

38. Suárez-Pereira I, Canals S, Carrión AM. Adult newborn neurons are involved in learning acquisition and long-term memory formation: the distinct demands on temporal neurogenesis of different cognitive tasks. Hippocampus. 2015;25:51-61.

39. Barker GR, Warburton EC. When is the hippocampus involved in recognition memory? J Neurosci. 2011;31:10721-31.

40. Chow ES, Hui MN, Lin CC, Cheng SH. Cadmium inhibits neurogenesis in zebrafish embryonic brain development. Aquat Toxicol. 2008;87:157-69.

41. Shim HJ, Park S, Lee JW, Park HJ, Baek SH, Kim EK, Yu SW. Extracts from Dendropanax morbifera leaves have modulatory effects on neuroinflammation in microglia. Am J Chin Med. 2016:44:119-32.

42. Bigbee JW, Sharma KV, Chan EL, Bögler O. Evidence for the direct role of acetylcholinesterase in neurite outgrowth in primary dorsal root ganglion neurons. Brain Res. 2000;861:354-62.

43. Koenigsberger C, Chiappa S, Brimijoin S. Neurite differentiation is modulated in neuroblastoma cells engineered for altered acetylcholinesterase expression. J Neurochem. 1997;69:1389-97.

44. Sklan EH, Berson A, Birikh KR, Gutnick A, Shahar O, Shoham S, Soreq H. Acetylcholinesterase modulates stress-induced motor responses through catalytic and noncatalytic properties. Biol Psychiatry. 2006:60:741-51.

45. Dori A, Cohen J, Silverman WF, Pollack Y, Soreq H. Functional manipulations of acetylcholinesterase splice variants highlight alternative splicing contributions to murine neocortical development. Cereb Cortex. 2005;15:419-30.

46. Kotani S, Yamauchi T, Teramoto T, Ogura H. Pharmacological evidence of cholinergic involvement in adult hippocampal neurogenesis in rats. Neuroscience. 2006;142:505-14.

47. Kotani S, Yamauchi T, Teramoto T, Ogura H. Donepezil, an acetylcholinesterase inhibitor, enhances adult hippocampal neurogenesis. Chem Biol Interact. 2008;175:227-30.

48. Saija A, Princi P, De Pasquale $R$, Costa G. The bioflavonoid O-( $\beta$ hydroxyethyl)-rutoside affects the cerebral metabolism and the permeability of the blood-brain barrier in the rat. Pharmacol Res. 1990;22 Suppl 1:69-70.

49. Ferri P, Angelino D, Gennari L, Benedetti S, Ambrogini P, Del Grande P, Ninfali P. Enhancement of flavonoid ability to cross the blood-brain barrier of rats by co-administration with a-tocopherol. Food Funct. 2015;6:394-400.

50. Habtemariam S. Rutin as a natural therapy for Alzheimer's disease: Insights into its mechanisms of action. Curr Med Chem. 2016:23:860-73.

\section{Submit your next manuscript to BioMed Central and we will help you at every step:}

- We accept pre-submission inquiries

- Our selector tool helps you to find the most relevant journal

- We provide round the clock customer support

- Convenient online submission

- Thorough peer review

- Inclusion in PubMed and all major indexing services

- Maximum visibility for your research

Submit your manuscript at www.biomedcentral.com/submit 